\title{
TEOGONÍA DE DERVENI Y GENEALOGÍA PLOTINIANA
}

\author{
Derveni theogony and Plotinian genealogy ${ }^{1}$
}

José M. Zamora Calvo*

\section{Resumen}

La teogonía de Derveni construye un relato complejo sobre la organización del mundo y el poder divino desde el comienzo de los tiempos. El último rey divino, el dios supremo del universo, Zeus, que también es su demiurgo, devora el falo de su padre, Urano, para poder así regresar él mismo a una generación anterior a la primera, dando inicio bajo su reinado a un nuevo ciclo cósmico. Para Plotino, la castración de Urano representa la transcendencia del Uno-Bien respecto a la Inteligencia, simbolizada por Crono; y el Alma, Zeus, que escapa a la voracidad de su padre, constituye el primer dios demiurgo, cuya función es la de servir de mediador entre lo inteligible y el mundo sensible.

Palabras clave: Papiro de Derveni, Plotino, teogonía, mito genealógico, hipóstasis, UranoCrono-Zeus.

\section{Abstract}

Derveni theogony constructs a complex narrative about the organization of the world and the divine power from the beginning of time. The last divine king, the supreme god of the universe, Zeus, who is also his demiurge, devours the phallus of his father, Uranus, in order to return himself to a generation before the first, giving birth under his reign to the beginning of a new cosmic cycle. For Plotinus, the castration of Uranus represents the transcendence of the One-Good with regard to Intelligence, symbolized by Kronos; and the Soul, Zeus, who escapes from the voracity of his father, is the first demiurge god, whose function is to serve as mediator between the intelligible and the sensible world.

Key words: Derveni Papyrus, Plotinus, theogony, genealogic myth, hypostases, UranusKronos-Zeus.

\section{INTRODUCCIÓN}

El Papiro de Derveni constituye un documento de excepcional relevancia para los actuales estudios de filosofía antigua. Descubierto en el año 1962, en un yacimiento al noroeste de Tesalónica, es el papiro griego más antiguo que conservamos, datado entre 340 y 320 a.C., y el único procedente de Grecia. El papiro presenta dos partes diferenciadas con claridad desde el punto de vista temático. ${ }^{2}$ La

\footnotetext{
${ }^{1}$ Este artículo se ha realizado en el marco del proyecto de investigación "Éticas griegas y filosofía contemporánea”, financiado por el Ministerio español de Ciencia e Innovación (Ref. FFI2009-09498).

${ }^{2}$ El autor anónimo del papiro cita y glosa varios versos de un poema atribuido a Orfeo, que debía de ser bastante breve, compuesto en torno a 500 a.C., que trata de explicar el sentido oculto de los versos por medio de un comentario filosófico. Según los actuales intérpretes, este poema, atribuido a Orfeo, debía de ser bastante breve (West, 1983:75 sq.; Tortorelli Ghidini, 1985; 1991; Burkert, 1998:389sq.;
} 
primera, que integra las columnas I-VII, incluida además la XX, se consagra a temas ceremoniales e iniciáticos, empleando una terminología específica de un sacerdote, un adivino o un profesional en rituales. Y, la segunda, que comprende las columnas VIIIXXVI, incluye la teogonía órfica más antigua, transmite testimonios sobre rituales, constituyendo el primer ejemplo conservado del comentario (hypómnema) de un poema verso a verso, ${ }^{3}$ donde se emplean análisis etimológicos semejantes a los del Crátilo y alegóricos, donde se entretejen concepciones estoicas, así como una terminología que presenta coincidencias con filósofos preplatónicos como Heráclito, Anaxágoras, Diógenes de Apolonia o Demócrito.

Este artículo trata de situar el estudio del Papiro de Derveni sobre un eje diacrónico, que permita aclarar mutuamente discursos religiosos pertenecientes a épocas y contextos diferentes - fragmentos de la teogonía original de Orfeo y el pensamiento genealógico de Plotino- trabajando en el marco metodológico y sobre las condiciones de validez de este enfoque diacrónico arduo.

\section{SOBERANÍA Y FUNCIÓN DEMIÚRGICA DE ZEUS}

Las explicaciones que contiene el papiro muestran que las interpretaciones del poema de Orfeo encerraban un saber oculto, que se dirige solo a iniciados. Así lo expresa desde el proemio, cuyo primer verso introductorio señala: "Hablaré a quienes es lícito; cerrad las puertas, profanos” (OF 3). No es, por tanto, un poema iniciático, sino que es pronunciado ante los ya iniciados (Bernabé, 2006:101; Bernabé y Casadesús, 2008:207, No 32), pues solo ellos, y no los profanos, pueden entenderlo (Bernabé, 1996a). A continuación, se referiría al "plan” de la obra, del que probablemente formaría parte el verso siguiente: "que nacieron de Zeus, el monarca más que poderoso" (Col. VIII 2; OF 4).

El poeta alude a los dioses y a los seres que nacieron de Zeus, que no es el primer progenitor, y únicamente de él, sin mencionar una pareja femenina. De este modo, el tema central del poema es la función demiúrgica de Zeus, que engendra los dioses y los seres que conformarán el mundo.

Tras este verso, que probablemente sería el último del proemio, el poeta sitúa la acción en el momento en que Zeus destrona a su padre Crono, y se apodera de su fuerza y del reino: "Zeus, cuando el poder de su padre, determinado por los dioses / tomó en sus manos, así como la fuerza y el glorioso demon” (Col. VIII 4-5).

\footnotetext{
1999:79; 2005; Bernabé, 1989, 2002; 2004:152sq.; Calame, 1997; Brisson, 1995; Casadesús, 1995, 1996; Laks y Most, 1997; Tsantsanoglou, 1997).

${ }^{3}$ Además de la edición autorizada del Papiro de Derveni, publicada por Leo. S. Olschki Editore en 2006, disponemos de un texto fiable elaborado por Janko (2002), y dos comentarios recientes, compuestos por Jourdan (2003) y Betegh (2004). En la actualidad, el "Center for Hellenic Studies” de la Universidad de Harvard coordina la versión electrónica de la editio princeps del Papiro (Kouremenos, Parássoglou y Tsantsanoglou, 2006), que los editores actualizan regularmente "en línea”: http://chs.harvard.edu/wa/pageR?tn=ArticleWrapper\&bdc=12\&mn=2174
} 
La soberanía de Zeus es legítima, ya que no se somete a cumplir su propio deseo de reinar, sino que viene "determinada por los dioses". Asimismo, arkhé no solo significa "poder”, sino también "principio”. En el relato genealógico, Zeus también es el primero de los dioses. Por su parte, "tomó en sus manos" alude al traspaso de poder, empleando una expresión habitual en las narraciones teogónicas (Fr. 101 y 102 Kern; Casadesús, 1995:247; Bernabé, 2002:102); y “el glorioso demon” se identifica con el padre, es decir, con Crono. En este punto, Bernabé (2002:102-103) se opone a la tesis de West (1983:84sq;114), que identifica daímon con Fanes Protogonos de las Rapsodias. De este modo, se refiere a cuando Zeus destrona a su padre Crono y se adueña de su reino. Tras derrocar a su padre, toma el poder en sus manos y se apropia de su fuerza, en tanto dios supremo, y del reino, el gobierno de cielo.

Este tema, presente también en la Teogonía de Hesíodo, aparece en este poema órfico del siguiente modo: tras tomar el poder, Zeus se dirige a la cueva de Noche para que le indique, de manera profética, cómo ha de proceder
Zeus [... llegó a la cueva donde] se sentaba Noche, sabedora de todos los oráculos, inmortal nodriza de los dioses, (para desde allí) vaticinar desde lo más recóndito.
Ella le vaticinó todo cuanto le era lícito lograr: cómo ocuparía la hermosa sede del nevado Olimpo (OF 6).

En las teogonías órficas esta diosa conoce todos los oráculos, dado su carácter primordial, al existir siempre, lo que le permite saberlo todo desde el principio de los tiempos. Y, de nuevo, el poeta reitera que la actuación de Zeus es legítima, a diferencia de la de sus antecesores, ya que considera "lícito" el modo de reinar sobre los dioses. Asimismo, Crono también le muestra de qué modo ha de continuar su labor creadora: “Zeus, una vez que oyó los vaticinios de su padre” (Col. XIII 1; OF 7).

El principal consejo que Zeus recibe de Crono o de la Noche es el que lleva a cabo en la Col. XIII 4: "Se tragó el falo (de Urano), que había eyaculado primero el éter (aidoîon katépinen, hòs aithéra ékthore prôtos)” (OF 8).

La mayor dificultad a la hora de interpretar este pasaje radica en una doble ambigüedad: 1) El término aidoîon puede significar "venerable" o "falo". ${ }^{4}$ Si se tratara de este último, sería el falo de Urano, que había sido castrado por su hijo Crono, coincidiendo también con el relato de la Teogonía hesiódica. Si se tratara de “venerable”, correspondería a Fanes Primogénito, personaje presente en las Rapsodias. Con Bernabé, preferimos la primera posibilidad, pues aidoîon en singular está documentado en autores antiguos, como Heródoto (II, 30 y 48). 2) Si consideramos aithéra como objeto directo de ékthore, podemos traducir el verbo como "eyaculó", refiriéndose prôtos al genitivo que depende de aidoîon, es decir, Urano.

\footnotetext{
${ }^{4}$ West (1983:85 sq.) y Lask y Most (1997:16) prefieren “venerable”. Contra ellos, optando por el órgano sexual, Burkert (1999:81-83; 2004:91-93); Janko (2002 ad loc); Bernabé (2002:104-118); y OF 12, 23. Una recopilación de esta discusión puede verse en Betegh (2004:112-122), y en Bernabé y Cadasedús (2008:291-324).
} 
En la Teogonía de Derveni Urano es Eufrónida, es decir, hijo de Noche, y fue “el primerísimo en reinar” (prótistos basíleusen) (Col. XIV 6; OF 10), a diferencia del relato hesiódico, donde lo primero es Caos y después Gea, que engendra de sí a Urano.

Zeus, que ha devorado el falo de Urano, queda embarazado del cosmos. Por ello, Zeus puede "gobernar" y "ser el primero" de los dioses, según el doble sentido de árkhein, ya que todos van a volver a nacer de él. Al recibir el poder, Zeus obtiene la astucia (mêtis) y la dignidad regia para reorganizar el mundo (Cfr. Col. XV 13-15; OF 11).

Como los hombres creían que la generación radicaba en los órganos sexuales, y que sin estos órganos no había posibilidad alguna de generación, en la Col. XIII 4-9 el poeta compara el sol con el falo (aidoîon). Si ponemos en relación este pasaje con el comienzo del la Col. XVI 1-3, Zeus, tras su ingestión del falo de Urano, ${ }^{5}$ queda preñado de todas las "posibilidades generativas” que existían en su padre.

Por la ingestión del falo de Urano, Zeus está dotado de una inmensa fecundidad, por la que puede procrear a todos los seres: "del falo del rey primogénito...” (Col. XVI 3; OF 12, 1).

Así, Zeus, al engullir el falo de Urano, reinicia el proceso de la generación de todos los seres, transformándose en el padre y la madre de todos: "y en él todos los inmortales se gestaron... y todo lo demás cuanto entonces había llegado a ser, así que él llegó a ser lo único” (Col. XVI 3-6; OF 12). Con la ingestión del falo de su padre, que pertenecía a la primera generación, Zeus ha asumido el poder de los dioses y su ingenio, convirtiéndose en la generación anterior a la primera. Como explica Bernabé, "la multiplicad se ha reducido a unidad, para volver a multiplicarse luego" (1998; 2008:301). Por ello, Zeus “nació el primero y el último” (OF 14, 1). El nacimiento del primogénito antecede al de su padre. Aplicando el análisis de la relación genealógica de parentesco: Zeus es hijo de Urano (diaíresis), pero al tragarse el falo de su padre, lo que está suponiendo, cuando realizamos la recomposición (synaíresis), una estructura jerárquica: Zeus toma el poder, al introducir el falo en sus entrañas, adquiere la dignidad regia y el ingenio con el que se inicia una nueva monarquía divina, donde el último rey nacido se convierte en el primogénito ("Zeus nació el primero, Zeus, el último, el de rayo refulgente" (OF 14, 1), en "el rey de todo"; "Ahora es rey de todo y en adelante lo será” (Col. XVI 14; OF 13).

Zeus se constituye en el dios centro, demiurgo del universo, que gobierna desde su trono y neutraliza todo oposición contra él. Este dios "del rayo refulgente" (OF 14), último transformado en primero, es soberano de todo, hálito y destino de todo. A diferencia de la generación anterior, sometida a la violencia y al caos, donde

\footnotetext{
5 “Devorar el falo (aidoîon)" se ha relacionado con un pasaje fragmentario del texto hitita Reinado en los cielos, de Kumarbi de Boghazköy, puesto en paralelo con Hesíodo desde su descubrimiento. Kumarbi devora la "virilidad" de Anu, dios Cielo, quedando embarazado de "terribles dioses" como el dios de la Tempestad, el río Tigris y Tasmisu, el visir de los dioses. Del vientre de Kumarbi sale la descendencia de Anu. Véanse Güterbock (1946:7; 1948:120); Bernabé (1987:146sq.); Hoffner (1998:42sq.); TUAT 829sq.; y Burkert (2008:584-585).
} 
los dioses luchaban por el poder, Zeus introduce orden en el mundo, siguiendo un designio preconcebido intelectualmente, vuelve a generar a todos los dioses, comenzando por "dar a luz” a Urano y a Gea.

En esta regeneración, Zeus se une incestuosamente con su madre, Rea, diosa que en la tradición órfica se identifica con Deméter (West, 1983:115): "Pero cuando la mente de Zeus hubo concebido todas sus obras / deseaba unirse en amor con su propia madre” (OF 18).

Desgraciadamente nuestra información sobre el poema órfico se detiene en este punto. Parece, como propone Bernabé (2002:122-123), que el propósito de Zeus al unirse a su madre trate de regresar atrás también en el plano sexual. Al convertirse en esposo de su propia madre, se vuelve padre de sí mismo e hijo de sí mimo. De este modo, rompe el ciclo de sucesiones en que los hijos destronaban a sus padres en el reinado olímpico. Al tomar como esposa a su madre, elimina la distinción entre las dos fases de generación del mundo, y, convertido ahora en "rey de todo” (OF 13), nunca en adelante podrá ser reemplazado por otro dios.

Seguramente el poema completo incluyera más información al respecto, ya que a nosotros solo nos han llegado fragmentos. Se han mencionado Noche, Urano y Crono, y probablemente pueden haber estado activos antes.

\section{GENEALOGÍA DE LOS DIOSES}

El poema atribuido a Orfeo citado en el comentario es denominado convencionalmente "teogonía”, es decir, "genealogía de los dioses", porque alude a los relatos míticos que se remontan al origen de los tiempos y que pueden hallarse, de una manera parcial, en otras teogonías, como las de Hesíodo y los órficos posteriores.

En Plotino, los tres grandes dioses de la teogonía hesiódica, presentes también con "rapidez narrativa” y sin un enfoque sistemático en la teogonía de Derveni, se corresponden a las tres hipóstasis principales:

$$
\begin{gathered}
\text { Urano - Uno-Bien } \\
\text { Crono - Inteligencia } \\
\text { Zeus - Alma }
\end{gathered}
$$

La genealogía que une a Urano, Crono y Zeus puede relacionarse con las tres hipóstasis plotinianas: el Uno-Bien, la Inteligencia y el Alma. Sin embargo, la relación entre estas tres hipóstasis no es genealógica, sino jerárquica, cada una ocupa un "rango" y una "potencia” específica que la distingue de la otra. Se trata de un tipo de relación semejante a la que se establece en la República de Platón entre el Bien y el sol. El uso de la relación genealógica de parentesco: el sol es hijo del Bien (diaíresis), pero el sol es inengendrado, lo que está suponiendo, cuando realizamos la recomposición (synaíresis), una estructura jerárquica en la que el Bien invisible ocuparía un rango y una potencia superior al sol visible. Según Lambros Couloubaritsis, "la relación genealógica remite a una estructura precisa y jerárquicamente fundada” (1990:90). Del esquema del parentesco y la lógica 
genealógica, que encontramos en el momento de diaíresis del mito, pasamos a una estructura no genealógica, sino jerárquica. Sin embargo, hemos de reconocer que gracias al análisis del mito podemos acceder por medio de lo genealógico a comprender lo inengendrado; lo invisible, por medio de lo visible.

Urano designa el Uno-Bien, aunque su nombre no se encuentre explícitamente en el texto, se sobreentiende en el contexto genealógico del que se trata. "Rey de rey y de Reyes (basileùs basiléos kaì basiléon). Sería más justo llamarle 'Padre de dioses' (patèr...theôn)” (En. V, 5 [32] 3, 20-21; trad,. Igal, 1998:104). La Inteligencia, sin embargo, constituye un dios de segundo rango, y se manifiesta antes que el primer principio, viene simbolizada por un trono, el Uno-Bien, a su vez, por un rey que tiene un puesto supremo en el cortejo, utilizando una descripción que nos recuerda las escenas que aparecen representadas en los mosaicos bizantinos (En. V, 5 [32] 3, 4-21).

A lo largo de toda la Enéada $\mathrm{V}$ encontramos trazada con frecuencia la correspondencia entre la segunda hipóstasis y Crono. El primer principio engendra la Inteligencia, y ella misma será la encargada de producir consigo todos los seres y las formas inteligibles; sin embargo, para impedir que caigan en la materia, los mantiene en su interior, por lo que se encuentra "saturada" de todos sus vástagos, los inteligibles, retenidos en su propio seno. Plotino va a comparar esta inclusión de los inteligibles en la Inteligencia con el mito de Crono que devora a cada uno de sus hijos cuando, desde el vientre de su compañera Rea, llegaban a sus rodillas (Hesíodo, Teogonía, 455-466), intentando con ello evitar la muerte a manos de uno de sus hijos, y que se cumpliera así la predicción de Gea y Urano (Hesíodo, Teogonía, 466-468).

y en que, grávido (plére) de su propia prole y habiéndola reabsorbido, por así decirlo, al retenerla en su propio seno, tampoco la deja diluirse en materia (eis hýlen) ni criarse en el regazo de Rea. Esto es lo que los misterios de los mitos teogónicos expresan enigmáticamente: que Crono, dios sapientísimo, antes de que naciera Zeus, retiene en su seno su propia prole. Por eso está grávido, es Inteligencia saturada (En. V, 1 [10] 7, 30-35; trad. Igal, 1998:34).

Crono simboliza a la Inteligencia (En. III, 5 [50] 2, 19-20). Según una etimología utilizada ya por los estoicos, que Plotino recoge de ellos, Crono (Krónos) es el dios que es "saciedad” (kóros) e "inteligencia” (noûs) (En. V, 1 [10] 4, 9-10). Cicerón también alude a esta aproximación: "Saturnus autem est appellatus, quod saturetur” (De natura deorum, II, 25-44 Ax). Si observamos, la correspondencia latina entre Saturnus y satur coincide con la griega entre Krónos y kóros, tal y como la establece Plotino. San Agustín, en su De consensu Euangelistarum, acude también a esta etimología estoica, transmitida por Cicerón, precisamente cuando explica este pasaje plotiniano. El término latino Saturnus, según se desprende de la interpretación agustiniana, sería un término híbrido, semi-latino y semi-griego, que se correspondería perfectamente con la "Inteligencia saturada" de Plotino si se escribiera Satur-noûs (I, 23-35). 
No obstante, si lo generado ha de parecerse a su generador, la Inteligencia al Uno, ¿Cómo el Uno, que no es Inteligencia, puede engendrar la Inteligencia?, ¿Cómo el Uno, que no es múltiple, puede producir la unidad-múltiple que constituye la Inteligencia? Para explicar la génesis de la Inteligencia, Plotino acude al discurso mitológico. Mientras la unidad de la Inteligencia es también pluralidad, el Uno no es pluralidad, sino potencia productora de la pluralidad (Cfr. John M. Rist, 1967:75-76).

Es verdad que también aquí, en la Inteligencia, el Centro es uno, pero el uno que es Potencia de todas las cosas (dýnamis pánton). Las cosas, pues, de las que el Uno es Potencia, estas la Intelección, desprendiéndolas, por así decirlo, de su Potencia, las ve. De lo contrario, no sería Inteligencia (En. V, 1 [10] 7, 9-11; trad. Igal, 1998:3. Cfr. Atkinson, 1983:164-165).

Por el axioma de la procesión sabemos que todos los seres, cuando alcanzan su estado de perfección, engendran (En. V, 1 [10] 6, 37-38). Esta idea también la expresa Plotino con la metáfora del desbordamiento: el Uno-Bien genera la Inteligencia, y esta el Alma, como una especie de desbordamiento de la "superabundancia” (tò hyperplêres) de sus respectivos principios (En. V, 2 [11] 1, 7-16). Cuando un ser llega a su perfección, está en condiciones de engendrar, en virtud de este principio de la productividad de lo perfecto, no ha de permanecer estéril. "Luego — prosigue el mito- una vez saturado, engendra a Zeus. Efectivamente, la Inteligencia, siendo ya Inteligencia perfecta, engendra el Alma" (En. V, 1 [10] 7, 35-37; trad. Igal, 1998:34). Ahora bien, no es posible que el ser generado sea superior a su generador, porque como se trata de una "imagen" (eídolon) de su generador, ha de ser necesariamente inferior (En. V, I [10] 7, 3740). Del mismo modo, el ser generado es indeterminado (aóristos), pero ha de ser determinado e informado por su generador, volviéndose contemplativamente a él.

Los inteligibles que la Inteligencia genera los conserva en su interior, solo el Alma, simbolizada por Zeus, logra escapar y autoconstituirse así como hipóstasis inferior. Precisamente, la actividad de los lógoi generados por el Alma se extenderá hasta los últimos confines de la procesión, hasta la materia sensible, designada por Rea, fluir permanente y multiplicidad. ${ }^{6}$ Frente a la

\footnotetext{
${ }^{6}$ El término 'Pé $\alpha$ presenta un doble significado: por una parte, es el nombre de la esposa de Crono; pero, por otra parte, conserva las connotaciones heraclíteas de flujo e inestabilidad. La interpretación heraclítea se basa en una lectura del Crátilo de Platón: « “-Sócrates: Me parece ver a Heráclito diciendo cosas sabias y añejas, simplemente de los tiempos de Rea y Crono; las mismas que Homero decía / -Hermógenes: ¿A qué te refieres con esto? / -Sóc.: En algún sitio dice Heráclito 'todo se mueve y nada permanece' y, comparando los seres con la corriente de un río, añade: ‘no podrías sumergirte dos veces en el mismo río’. / -Herm.: Eso es. / -Sóc.: ¿¿Pues qué? ¿Piensas que quien puso el nombre de Rhéa y Krónos a los progenitores de los demás dioses pensaba algo distinto que Heráclito?”, (Platón, Crátilo, 402 a 2-b 2). Sin embargo, Proclo, comentando este mismo pasaje, cree que una interpretación de este tipo es indigna del pensamiento de Platón (Cfr. Proclo, In Cratylum, 80, 16 ss. [Pasquali]). Sobre este punto, véase el comentario de Michael J. Atkinson (1983:178-179).
} 
estabilidad de los inteligibles (que permanecen perfectos en el seno de la Inteligencia, sin contaminarse con la dispersión propia de la materia y el mundo sensible), Plotino menciona a Rea, para referirse a la materia sensible.

En el siglo I d.C., el estoico Cornuto aplica el método alegórico a la mitología. En su Compendio de Teología griega interpreta un fragmento de la Teogonía, donde Hesíodo trata el tema de las bodas de Crono y Rea. Cornuto encuentra en las luchas divinas por la conquista de la soberanía celeste una expresión de la cosmología estoica, donde Urano designa el cielo o el éter que abarca todos los seres; Crono, el tiempo, según una etimología sencilla cuyo posible origen se remonte a los órficos (Cfr. Enrique A. Ramos Jurado, 1981:148 y 1990:77); Rea, que significa etimológicamente "fluir" (rheîn), es la tierra; y Zeus, el Alma del mundo. La boda de Crono y Rea simboliza la unión del tiempo y el mundo, sin el que este último no podría existir. ${ }^{7}$ Todo lo que dure el tiempo, durará el mundo, y a la inversa. De la unión del tiempo y la tierra surge la totalidad de las cosas. Pero el tiempo, Crono, devora todo, excepto aquello que es inmortal, Zeus, principio de vida, ${ }^{8}$ que representa el Alma del mundo.

\section{LA CASTRACIÓN DE URANO}

La exégesis alegórica de Cornuto se basa en la física y cosmología estoicas. Así, Crono devorando a sus hijos representa el tiempo que absorbe el devenir nacido de él (Cfr. Jean Pépin, 1958:158-159). A diferencia de la hermenéutica plotiniana, Cornuto aplica a los dioses de Hesíodo nociones de la filosofía estoica, y con este fin se sirve de la etimología. En la teogonía de Derveni, Zeus engulle el falo de Urano, lo que da lugar al embarazo cósmico. Por su parte, para Plotino, la castración de Urano representa la transcendencia del primer principio en relación a la Inteligencia, simbolizada por Crono. En la cosmogonía hesiódica Urano se encuentra tendido sobre Gea, cubriéndola totalmente, pero ocultando tanto a ella, sobre la que está echado, como a sus hijos, a los que les impide salir del seno materno. Urano no quiere que sus hijos se interpongan entre él y Gea, por lo que no les deja que escapen del vientre de su madre. Pero Gea convence al más joven de sus hijos, Crono, para que, cuando Urano se tumbe sobre ella, le siegue los órganos sexuales con una hoz. A partir de entonces, el Padre-Cielo queda separado para siempre de la Madre-Tierra. El mundo ha dejado de permanecer inmóvil y comienza a producirse la génesis. El espacio y la duración creados entre el Cielo y la Tierra hace que se genere la multiplicidad de seres. Urano castrado se ha quedado solo y aislado por la hoz de su hijo, Crono, pero únicamente así fue posible el nacimiento de sus hijos.

\footnotetext{
${ }^{7}$ Tema platónico que parte del Timeo, 37e-38b.

${ }^{8}$ Cornuto relaciona Zeus (Zeús) con el verbo “vivir” (zên), etimología de origen estoico que proviene de Crisipo, para quien el nombre de Zeus procede de "lo que ha hecho a todo vivir (zên)" (SVF, II, 1062:312). Pero esta etimología aparece ya en el Crátilo de Platón: "Ese dios se encuentra pues justamente nombrado, aquel por el que (di’ hòn) todos los seres vivos obtienen la vida (zên)”, Crátilo, 396b.
} 
En las Rapsodias y en Hesíodo el padre de Crono es Urano. En el pasaje del Papiro de Derveni, el comentador anónimo menciona el sol en lugar de Urano como padre de Crono, mientras que en la secuencia de la transmisión del poder, el poeta nos presenta la genealogía habitual: Urano-Crono-Zeus. Parece posible considerar el falo de Urano como una metáfora del sol (Bernabé, 2002:110). El poeta señala que Zeus integra por deglución todo lo que había sido creado antes de él; y asimismo Zeus se halla preñado de todas las potencialidades generativas que contenía el falo del primer dios de la serie, Urano.

Para Plotino, Urano, el Padre-Cielo castrado por su hijo Crono, simboliza la transcendencia del Uno respecto a la Inteligencia. El Uno-Bien permanece en sí mismo, más allá del ser y el pensar, mutilado no puede volver a reproducirse, y cede su función generadora a la Inteligencia. No obstante, Zeus, el Alma, escapa a la voracidad de su padre, gracias a la astucia de Rea, la materia, y derroca a su padre Crono. El Alma, engendrada por la Inteligencia, va a extender su actividad hasta el ámbito de lo sensible, mientras su progenitor permanece inmutable en su dominio inteligible. Como Crono, la Inteligencia encierra a su descendencia, los inteligibles, en el interior de su seno. Pero pasa a ser el Alma, simbolizada por Zeus, quien extienda su actividad hasta el ámbito sensible. ${ }^{9}$

Zeus es el único hijo que se salva de ser devorado por su padre, y el único que le vence. La Inteligencia, repleta de inteligibles, genera el Alma, cuya función es servir de mediadora entre la Inteligencia y el mundo sensible, para lo que transmite una imagen de los inteligibles, los lógoi, a la materia sensible. De este modo, Zeus, símbolo del Alma hipóstasis, no se ha detenido en la contemplación de su padre, sino que se une a la soberanía de su abuelo, Urano, "rey de rey y de reyes y padre de los dioses” (En. V, 5 [32] 3, 20-21).

Sin embargo, en las Enéadas, Zeus puede representar no solo el papel del Alma, en tanto tercera hipóstasis, sino también el del alma del mundo, ordenadora del universo, que recupera las funciones propias del demiurgo platónico.

Empero Zeus, que ordena todas las cosas y las administra y dispone por siempre, que posee "un alma regia y una inteligencia regia (psykhèn basilikèn kaì basilikòn noûn)" y una mente provisora de cómo han de suceder las cosas

\footnotetext{
9 “Así pues, el dios (Crono) que está encadenado (dedeménos) a una existencia permanente e invariable y que cedió a su hijo (Zeus) el mando de este universo (porque no decía bien con su modo de ser abdicar aquel mando y asumir este otro, más reciente y posterior, estando él como está repleto de seres bellos), desechando las cosas de acá, fijó a su propio padre (Urano) en su debido puesto, y a los seres del lado opuesto que derivan de su hijo (Zeus) los fijó en la zona contigua inferior, de manera que él quedara en medio de ambos (metaxý), deslindado de la zona de arriba mediante la alteridad de la 'amputación' y de la zona de abajo mediante las 'ataduras' que lo separan del que viene a continuación, en medio (metaxý) de un padre mejor que él y de un hijo inferior a él” (En. V, 8 [31] 13, 1-11; trad. Igal, 1998:161).
} 
y supervisora de las que están sucediendo, que gobierna ordenadamente y hace girar rotatoriamente (En. IV, 4 [28] 9, 1-5; trad. Igal, 1985:386). ${ }^{10}$

Plotino se basa en un pasaje del Filebo, donde Platón habla de "una alma regia” y "una inteligencia regia”, ${ }^{11}$ para atribuir a Zeus un doble simbolismo: como la Inteligencia en sí o demiurgo y como la inteligencia del Alma superior o principio rector del universo.

Pero puesto que solemos hablar del principio ordenador como doble: de un lado, como el demiurgo, y de otro, como el Alma del universo, así también, al hablar de Zeus, nos referimos a él unas veces como al demiurgo y otras como al Rector del universo (En. IV, 4 [28] 10, 1-4; trad. Igal, 1985:387).

En un caso, Plotino identifica a Zeus con la Inteligencia, con lo que pasaría a ocupar la función de Crono; y, en otros casos, con el Alma rectora del universo, inteligencia del Alma superior. Esta polisemia característica de la hermenéutica plotiniana no era común entre los exégetas antiguos de Homero y Hesíodo; así por ejemplo, entre los estoicos, como Cleantes, Crisipo o el ya mencionado Cornuto, la correspondencia era más rígida entre cada personaje mítico y las nociones físicas o cosmológicas propias de su sistema.

\section{LA CRÍTICA DEL GNOSTICISMO}

Según Pierre Hadot (1981b), la exégesis alegórica que lleva a cabo Plotino de la tríada Urano-Crono-Zeus puede insertarse dentro de la crítica general a las teorías gnósticas. Los tratados en los que Plotino alude a los tres dioses de la cosmogonía hesiódica y de la teogonía de Derveni coinciden curiosamente con aquellos que dirige contra los gnósticos: Sobre la naturaleza, la contemplación y el Uno (En. III, 8 [30] 11, 35-43), Sobre la belleza inteligible (En. V, 8 [31] 12, 3-13 y 13, 1-11), Que los inteligibles no están fuera de la Inteligencia y sobre el Bien (En. V, 5 [32] 3, 16-24), y el propio tratado Contra los gnósticos (En. II, 9 [33] 2, 12). ${ }^{12}$ ¿Podemos pensar que se trata de una simple coincidencia? Parece que no, ya que si seguimos una lectura atenta, como sugiere Hadot, el leitmotiv que recorre este cuarteto de tratados, donde aparecen los tres

\footnotetext{
${ }^{10}$ Sobre este doble simbolismo de Zeus, véase también un pasaje del tratado Sobre el amor, donde Plotino cita también el mismo texto del Filebo (Cfr. nota siguiente): "Pero en el Filebo se expresa más claramente cuando dice que 'en Zeus hay un alma regia y una inteligencia regia”” (En. III, 5 [50] 8, 9-11; trad. Igal, 1985:138).

${ }^{11}$ Platón, Filebo, 30 d 1-2: "Entonces dirás que en la naturaleza de Zeus hay, por efecto de la causa, un alma de rey y un intelecto de rey".

${ }^{12}$ Este tratado comienza justo donde termina el anterior en orden cronológico, En. V, 5 [32]. Los tratados mencionados: II, 8 [30], V, 8 [31], V, 5 [32] y II, 9 [33] fueron compuestos en el segundo período y se suceden en el tiempo (Cfr. Porfirio, Vida de Plotino, 5, 26-34); aunque su discípulo y editor Porfirio los divida, pueden agruparse bajo el tema central de la crítica a los gnósticos, o como dice el título: "Contra los que dicen que el demiurgo del cosmos es malo y que el cosmos es malo” (ibidem, 24, 56-57).
} 
dioses de una forma más o menos directa, es la crítica al gnosticismo. ${ }^{13}$ Pero, ¿Cómo esta tríada le puede servir a Plotino para este fin? Urano engendra a Crono, y este, a su vez, genera a Zeus, de un modo semejante a como el Uno-Bien produce la Inteligencia, y esta el Alma. El mecanismo de la procesión se activa cuando el producto regresa contemplativamente a su productor, y no, como defendían los gnósticos, por un tipo de razonamiento o elección. Para Plotino, el mundo sensible es una imagen del mundo inteligible por la acción mediadora del Alma.

El Uno-Bien es el primer principio, pues no proviene de otro, ni está en otro, ${ }^{14} \mathrm{ni}$ es compuesto, por lo que por encima de él no hay nada (En. II, 9 [33] 1, 1-12). Después del Uno-Bien, absolutamente simple y autosuficiente, se hallan, en dos niveles jerárquicos diferentes, la Inteligencia y el Alma. En el mundo inteligible solo hay estas tres hipóstasis, realidades jerárquicamente estructuradas, y no puede haber más ni menos, porque si se postularan menos, habría que identificar el Alma con la Inteligencia o bien la Inteligencia con el Uno-Bien. Sin embargo, tampoco puede haber más de tres, pues no hay un primer principio en potencia y otro en acto, ni una Inteligencia en reposo y otra en movimiento, ni una que piensa y otra que piensa que piensa, ni un lógos independiente e intermediario entre la Inteligencia y el Alma (En. II, 9 [33] 1, 11-63). Por tanto, en el mundo inteligible solo hay que admitir las tres hipóstasis principales, sin que sea preciso establecer "distinciones conceptuales superficiales" que admitan exclusivamente una sola Inteligencia como única hipóstasis.

En contra de la concepción gnóstica del "Límite" (Hóros) que separa el mundo superior (Pléroma) del cosmos, Plotino defiende la continuidad entre el mundo inteligible y el sensible, gracias a la función mediadora del Alma.

Por siempre, pues, iluminada y poseyendo la luz perpetuamente, la transmite a las cosas siguientes; y estas se mantienen siempre consistentes e irrigadas gracias a esa luz, y disfrutan de su porción de vida en la medida de su capacidad, como si, habiendo una hoguera situada en el medio, se calentaran aquellas a las que les fuera posible (En. II, 9 [33] 3, 1-4; trad Igal, 1982:496).

Todos los niveles de la realidad inferiores al Uno-Bien son el resultado de un doble movimiento: uno de despliegue o proódico, y otro de repliegue o epistrófico.

13 Plotino tuvo contactos frecuentes con gnósticos que acudían a su escuela en Roma. Posiblemente pertenecían a los valentinianos. Tres son las tesis fundamentales del gnosticismo: la depreciación de la materia, la oposición entre un Dios supremo y un Dios creador, y la existencia de una revelación especial, al margen de la Escritura y dirigida a una minoría. El valentinismo estructura su sistema filosófico-teológico partiendo de los conceptos extraídos del platonismo tardío. Los gnósticos valentinianos admitían un dualismo cosmológico: entre el mundo superior (Pléroma) y el inferior (Kéroma) hay una diferencia insalvable, con un espacio intermedio (ogdóada) que participa de ambos. Este dualismo cosmológico se traduce también en el antropológico: separación radical entre el alma y el cuerpo, y entre el alma superior y el alma inferior. En su cosmogonía interviene un demiurgo, que ordena a partir de una “deliberación”, y es ayudado por demiurgos inferiores. (Cfr. Josep Montserrat Torrents, 1983, vol. I:39-40).

14 Todo lo que está en otro también proviene de otro, Cfr. En. V, 5 [32] 12-13. 
Plotino describe el reino de Crono, representando a la Inteligencia, como un mundo de luz y transparencia, sin nada de obscuridad, y donde cada parte se encuentra en perfecta igualdad e identidad con cada una de las otras, donde todo está por todas partes, cada parte es todo, y el esplendor carece de límites.

En la exégesis plotiniana del mito desaparece cualquier signo de "catástrofe". Plotino descubre en la sucesión genealógica de Urano-Crono-Zeus las fases de un proceso en el que se distinguen tres diferentes niveles de realidad jerárquicamente estructurados. El alejandrino "neutraliza” (Pierre Hadot, 1981b:134) cualquier idea de catástrofe o desastre dentro del esquema procesional. En contra de la concepción pesimista de los gnósticos, el mundo sensible no ha de ser despreciado, ya que constituye el reflejo de la luz y la belleza de los inteligibles. El Alma es la encargada de transmitir esa belleza contemplando eternamente a su progenitor, la Inteligencia.

Plotino entabla una polémica constante con los gnósticos, y para ello acude en este caso a un mito de la teogonía hesiódica, presente también en la teogonía de Derveni, del que extrae con habilidad las imágenes que le permiten expresar claramente su propio sistema (En. V, 8 [31] 10-13. Cfr. Pierre Hadot, 1981a:205214). De este modo, frente al pesimismo que empaña la filosofía y teología gnóstica, Plotino afirma que existe un mundo repleto de perfección y belleza, el reino de Crono (la Inteligencia) que no nos es extraño, pues su hijo Zeus (el Alma) ha sido el encargado de revelárnoslo.

Porque complacido de los seres que engendró y maravillado de su prole, retuvo cabe sí todas las cosas, gozoso de su propio esplendor y del de su prole. Mas siendo bellos y aun más bellos los que se quedaron en su seno, uno solo de entre sus hijos, Zeus, apareció al exterior. Y a partir de este hijo, que es el benjamín, es posible vislumbrar, como a partir de la imagen que es, la grandeza de aquel padre suyo y de aquellos hermanos suyos que se quedaron en el seno paterno (En. V, 8 [31] 12, 5-11; trad. Igal, 1998:160).

El Alma ha salido fuera de la Inteligencia y, en tanto imagen de su progenitor, transmite la luz y belleza de ella y sus hermanos, los inteligibles, a la materia sensible. De este modo, el Alma engendra un segundo mundo, que también participa de la belleza, porque es una imagen del mundo inteligible, su productor; por tanto, no puede ser feo ni malo. La belleza y el ser le vienen de su modelo, el mundo inteligible. Pero además, el mundo sensible es eterno, porque la imagen tiene que permanecer tanto como el modelo. Si el mundo inteligible es eterno, el sensible lo será también, en tanto imagen suya que es. De ahí que el mundo sensible no sea el producto malo de un demiurgo malo, como defendían los gnósticos, ni tampoco puede ser destruido, pues no es creado a partir de la deliberación de su productor.

Y por eso no tienen razón los que, mientras perdura el mundo inteligible, destruyen y generan el mundo sensible cual si fuera obra del designio deliberado de su Hacedor en un momento dado. Sea cual fuere el modo como se conciba esta creación, no quieren comprender ni saben que, mientras aquel 
siga resplandeciendo, nunca jamás cesarán las demás cosas, sino que, desde que aquel existe, también estas existen, y siempre existieron y existirán (En. V, 8 [31] 12, 20-25 (trad. Igal, 1998:161).

De este modo, en el mundo sensible se refleja la belleza del mundo inteligible (el reino de Crono), gracias a la función mediadora del Alma (Zeus) que contempla la belleza de los inteligibles (sus hermanos) contenidos en el interior de la Inteligencia. Así, el Alma transmite al mundo sensible los lógoi, imágenes de los inteligibles que contempla en el interior de la Inteligencia. El mito genealógico le sirve, según esto, para combatir a sus rivales, los gnósticos.

\section{CONCLUSIONES}

La teogonía interpretada en el Papiro de Derveni constituye un texto fascinante que, desgraciadamente, nos ha llegado de manera fragmentaria, viéndonos obligados a reconstruir, como arqueólogos un mosaico, partiendo de los datos que nos transmite un comentador anónimo.

La teogonía de Derveni construye un relato complejo sobre la organización del mundo y el poder divino desde el comienzo de los tiempos. Desde luego, podemos trazar muchos paralelismos y descubrir diversas disonancias con el texto de la Teogonía de Hesíodo y la genealogía plotiniana. El último rey divino, el dios supremo del universo, Zeus, que también es su demiurgo, siguiendo un designio preconcebido e inteligente, devora el falo de su padre, Urano, para poder así regresar él mismo a una generación anterior a la primera, dando inicio bajo su reinado a un nuevo ciclo cósmico.

En las Enéadas un mismo personaje mítico le sirve a Plotino para designar varias nociones filosóficas; $y$, a la inversa, una noción filosófica puede recibir diversas representaciones míticas, sin que sea posible establecer una correspondencia exacta -término a término- entre el discurso mítico, oblicuo, y el discurso directo (Pépin, 1955:480-481). Un buen lector de Plotino, como Bergson, afirma que las imágenes, cuando las utilizan los filósofos, no están destinadas a revelar lo que son, sino a comunicar una intuición filosófica imposible de formular en conceptos. Para Bergson (1934), la imagen, aunque sea concreta, se halla más próxima de la intuición que el concepto, y es anterior a él. En opinión de Bréhier (1949:105), la imagen es el único medio de mantener en activo el pensamiento de Bergson y Plotino. Sin embargo, para ello no hay que tomar las imágenes como si fueran dogmas, según hicieron los adversarios de Bergson. Aquí radica precisamente el peligro del bergsonismo, ya que solo existen impresiones subjetivas o conceptos fundamentales. El uso de las imágenes nos es útil precisamente cuando desprendemos de ellas los elementos antropocéntricos que interpretan la realidad a partir de las prácticas familiares, y dirigimos nuestro conocimiento a una intuición.

Los mitos nos instruyen a su manera, pero es necesario corregir su óptica, un tanto deformadora de la realidad, ya que el discurso mítico divide lo que es uno, y 
despliega en el tiempo una realidad sincrónica o, mejor dicho, que transciende lo temporal. Después de escuchar o leer la diaíresis que lleva a cabo el mito de la realidad, es necesario, para llegar a una buena compresión del discurso mítico, realizar la recomposición (synaíresis), y reconstruir así la concentración primitiva. El mito genealógico suministra un instrumento muy útil para el análisis filosófico, precisamente porque divide temporalmente una realidad simultánea. Se trata de una expresión cómoda, ya que se basa en los datos más comunes y conocidos de la experiencia humana, como son las relaciones de parentesco, y sirve para traducir los momentos más difíciles de la exposición filosófica, como es el caso de las realidades inefables, las características de la materia y la génesis del mundo sensible. Para los neoplatónicos se hace necesario utilizar la expresión mítica, oblicua, a fin de acceder a la comprensión de nociones ante las que el lenguaje directo se encuentra en un terreno intransitable.

El relato de la teogonía de Derveni retoma, en líneas generales, como Plotino, la de Hesíodo, pero de una manera muy concisa: Crono emascula a Urano y lo expulsa del poder, para ser, a su vez, destronado por Zeus. La castración de Urano, para Plotino, representa la transcendencia del Uno-Bien respecto a la Inteligencia, simbolizada por Crono; y el Alma, Zeus, que escapa a la voracidad de su padre, constituye el primer dios demiurgo, cuya función es la de servir de mediador entre lo inteligible y el mundo sensible.

Universidad Autónoma de Madrid*

Facultad de Filosofía y Letras

Departamento de Filosofía

Campus de Cantoblanco. E-28049 Madrid (España)

jm.zamora@uam.es 


\section{BIBLIOGRAFÍA}

Arnim, Hans Friedrich August von, ed. Stoicorum Veterum Fragmenta. 4 vols. Leipzig: Teubner, 1905-1924.

Atkinson, Michael J. Plotinus: Ennead V, 1. On the three principal hypostases. A commentary with translation, Oxford: Oxford University Press, 1983.

Ax, Wolfram, ed. M. Tulli Ciceronis Scripta quae manserunt omnia. De natura deorum- Lepizig: Teubner, 1964.

Bergson, Henri. La pensée et le mouvement. Paris: P.U.F., 1934.

Bernabé, Alberto. “Teogonías órficas”, en A. Bernabé y F. Casadesús, eds. 2008. 291-324.

"Máxor en el Papiro de Derveni: ¿Magos persas, charlatanes u oficiantes órficos”, en E. Calderón, A. Morales y M. Valverde, eds. Koinòs lógos. Homenaje al profesor José García López. Murcia: Universidad de Murcia, 2006:99-109.

------ Poetae Epici Graeci. Testimonia et fragmenta. Pars. II. Orphicorum et Orphicis similium testimonia et fragmenta. Fasciculi 1 et 2. Munich y Leipzig: K. G. Saur, 2004-2005. (=OF).

------- Textos órficos y filosofía presocrática. Materiales para una comparación. Madrid: Trotta, 2004.

------- “La théogonie orphique du papyrus de Derveni”, en Kernos 15 (2002): 91-129.

------- "Lo uno y lo multiple en la especulación presocrática: nociones, modelos y relaciones”, en Taula, quaderns de pensament 27-28 (1998):75-99.

------- "La formula órfica 'cerrad las puertas, profanos'. Del profano religioso al profano en la materia”, en 'Ilu 1 (1996):13-37.

------- "Generaciones de dioses y sucesión interrumpida. El mito hitita de Kumarbi, la Teogonía de Hesíodo y el Papiro de Derveni”, en Aula Orientalis 7 (1989):159-179.

Textos literaios hititas. Madrid: Alianza, 1987.

Bernabé, Alberto y Casadesús, Francesc, eds. Orfeo y la tradición órfica. Un reencuentro. 2 vols. Madrid: Akal, 2008.

Betegh, Gabor. The Derveni Papyrus. Cosmology, Theology, and Interpretation. A preliminary reading, critical edition and translation, Cambridge: Cambridge University Press, 2004.

Bréhier, Emile. Études de philosophie antique, Paris: P.U.F., 1955.

------ “Images plotiniennes, images bergsoniennes”, en Les études bergsoniennes 2 (1949):105-128. (=Id. 1955, 292-307).

Brisson, Luc. Orphée et l'Orphisme dans l'Antiquité gréco-romaine. Aldershot: Variorum, 1995.

Burkert, Walter. "El dios solitario. Orfeo, fr. 12 Bernabé, en contexto", en A. Bernabé y F. Casadesús, eds. (2008):579-590. 
Da Omero ai Magi. La tradizione orientale nella cultura greca, Venecia: Marsilio, 1999.

“Die neuen orphischen Texte: Fragmente, Varianten, 'Sitz im Leben’”, en W. Burkert, L. Gemelli Marciano, E. Matelli y L. Orelli, eds. Fragmentsammlungen philosophischer Texte der Antike. Gotinga: Vandenhoeck \& Ruprecht, (1998):387-400.

Burnet, John, ed. Platonis Opera, 5 vols., Oxford: Clarendon Press, 1900-1907.

Calame, Claude. "Figures of Sexuality and Initiatory Transition in the Derveni Theogony and its Commentary”, en A. Laks y G. W. Most, eds. 1997. 6580.

Casadesús, Francesc. "Métis, el noûs, el aire y Zeus en el Papiro de Derveni”, en Faventia 18 (1996):75-88.

------- Revisió de les principals fonts per a l'estudi de l'orfisme a l'epoca classica. (Plató i el Papir de Derveni). Tesis Doctoral. Bellaterra: Universitat Autònoma de Barcelona, 1995.

Couloubaritsis, Lambros. "De la généalogie à la genèséologie”, en J.-F. Mattéi, ed. La naissance de la raison en Grèce. Actes du Congrès de Nice, mai 1987. París: P.U.F., (1990):83-96.

Güterbock, Hans Gustav. "The Hittite Version of the Hurrian Kumarbi Myth: Oriental Forerunners of Hesiod”, en American Journal of Archaeology 5 (1948):123-34.

------- Kumarbi. Mythen vom churritischen Kronos. Zürich-Nueva York: Europaverlag, 1946.

Hadot, Pierre. Plotin. Traité 50. Introduction, traduction, commentaire et notes par P. Hadot, París: Cerf, 1990.

"Images mythiques et thèmes mystiques dans un passage de Plotin", en Néoplatonisme, mélanges offerts à Jean Trouillard. Fontenay-aux-Roses: Les Cahiers de Fontenay, 1981a. 205-214.

------- “Ouranos, Kronos and Zeus in Plotinus' treatise Against the Gnostics”, en H. J. Blumenthal y R. A. Markus, eds. Neoplatonism and early Christian thought. Essays in honour of A. H. Armstrong. Londres: Variorum, 1981b:124-137.

Henry, Paul y Schwyzer, Hans-Rudolf, eds. Plotini Opera. 3 vols. Oxford: Clarendon Press, 1964-1982. (editio minor).

------ Porphyrii Vita Plotini. Oxford: Clarendon Press, 1964.

Hoffner, Harry A. Hittite Myths. Second Edition Revised and Augmented. Atlanta: Scholars Press, 1998.

Igal, Jesús. Plotino. Enéadas I-VI. 3 vols. Madrid: Gredos, 1982-1998.

Kern, Otto. Orphicorum Fragmenta. Berlín: Weidmann, 1922.

Kouremenos, Theokritos, Parássoglou, George M. y Tsantsanoglou, Kyriakos. The Derveni Papyrus. Edited with introduction and commentary. 
Florencia: Leo S. Olschki Editore, 2006.

Kaiser, Otto, ed. Texte aus der Umwelt des Alten Testaments, Gütersloh: Gütersloher Verlagshaus Gerd Mohn, 1982-2001. (=TUAT).

Janko, Richard. "The Derveni Papyrus: an Interim Text”, en Zeitschrift für Papyrologie und Epigraphik 141 (2002):1-62.

Jourdan, Fabienne. Le Papyrus de Derveni. París: Les Belles Lettres, 2003.

Laks, André y Most, Glenn W., eds. Studies on the Derveni Papyrus. Oxford: Clarendon Press, 1997.

------- “A Provisional Tranlation of the Derveni Papyrus”, en A. Laks y G. W. Most, eds.1997:9-22.

Lang, Carl, ed. Cornutus. Theologiae graecae compendium. Leipzig: Teubner, 1881.

Migne, Jacques-Paul, ed. Augustinus Hipponensis. De consensu evangelistarum, en Patrología latina. t. 34. París: Garnier Frères, 1844-1865.

Montserrat Torrents, Josep. Los gnósticos. 2 vols. Madrid: Gredos, 1983.

Pasquali, Giorgio, ed. Proclus. In Platonis Cratylum commentaria. Leipzig: Teubner, 1908.

Pépin, Jean. Mythe et allégorie. Les origines grecques et les contestations judéochrétiennes, París: Montaigne, 1958.

"Plotin et les mythes", en Revue philosophique de Louvain 53 (1955):527. (=Id., 1958:190-209).

Ramos Jurado, Enrique Ángel. “Mito y filosofía en el Neoplatonismo”, en Cinco lecciones sobre la cultura griega. Sevilla: Universidad de Sevilla, 1990. 71-88.

------- Lo platónico en el siglo V d. C.: Proclo. Sevilla: Universidad de Sevilla, 1981.

Rist, John M. Plotinus: the road to reality. Cambridge: Cambridge University Press, 1967.

Solmsen, Friedrich, Merkelbach, Reinhold y West, Martin Litchfield, eds. Hesiod Theogonia, Opera et Dies, Scutum, Fragmenta Selecta. Oxford: Clarendon Press, 1990.

Tortorelli Ghuidini, Marisa. "Due noivi teonimi orfici nel Papiro di Derveni”, en Ph. Borgeaud ed. Orphisme et Orphée. En l'honneur de Jean Rudhardt. Ginebra: Droz, 1991:249-261.

------- “Eufrono: una divinità orfica?”, en La Parola del passato 40 (1985):419425.

Tsantsanoglou, Kyriakos. "The First Columns of the Derveni Papyrus and their Religious Significance”, en A. Laks y G. W. Most, eds. 1997:93-128.

West, Martin Litchfield. The Orfic Poems. Oxford: Clarendon Press, 1983. 